\title{
Management of intrahepatic splenosis: a case report and review of the literature
}

Zefeng Xuan ${ }^{1,2}$, Jian Chen ${ }^{1,2}$, Penghong Song ${ }^{1,2}$, Yehui Du ${ }^{1,2}$, Lijun Wang $^{3}$, Dalong Wan ${ }^{1}$ and Shusen Zheng ${ }^{1,2^{*}}$

\begin{abstract}
Background: Splenosis is the heterotopic autotransplantation and implantation of splenic tissue after splenic trauma or splenectomy. Considering that splenosis often occurs in the mesentery, omentum, and peritoneum, intrahepatic splenosis has seldom been reported. We report a rare case of isolated intrahepatic splenosis in a 54-year-old man who presented with a liver mass thought to be hepatocellular carcinoma.

Case presentation: A 54-year-old man was referred to our hospital for further evaluation of a liver lesion. The patient was asymptomatic and had a history of emergent splenectomy after a high-altitude falling accident. Abdominal contrast-enhanced computed tomography revealed a $4.5 \times 3.3 \mathrm{~cm}$ lesion that was located in segment IV of the left liver lobe. The lesion had an inhomogeneous enhancement during the arterial phase and diminished enhancement during the portal and equilibrium phases. Similar radiological features were also observed on a contrast magnetic resonance imaging scan. Partial hepatectomy was performed with the suspicion of hepatocellular carcinoma. Pathological examination of the liver specimen revealed intrahepatic splenosis.

Conclusion: Splenosis should be considered in differential diagnosis of a liver mass discovered years after splenic trauma or surgery. A proposed scoring system may be helpful in evaluating the suspicious degree of intrahepatic mass to be splenosis. Invasive treatments are not recommended for asymptomatic patients, since the splenosis can provide beneficial immunologic function.
\end{abstract}

Keywords: Liver neoplasm, Intrahepatic splenosis, Splenectomy, Trauma

\section{Background}

Splenosis is the heterotopic autotransplantation of splenic tissue throughout the peritoneal and pelvic cavities, even the thoracic cavity, following splenic trauma or elective splenectomy [1]. The splenic fragments usually seed onto exposed vascularized peritoneal surface, receiving blood supply from the surrounding tissue. Intrahepatic splenosis is quite rare, as the majority of splenosis reported in the English literature was found to be located in the mesentery, omentum, and peritoneum [2]. The lack of typical radiological features makes it difficult to distinguish splenosis from liver tumors and reach a correct diagnosis. Herein, we present a case of isolated intrahepatic splenosis and summarize the

\footnotetext{
* Correspondence: shusenzheng@zju.edu.cn

${ }^{1}$ Division of Hepatobiliary and Pancreatic Surgery, Department of Surgery,

First Affiliated Hospital, School of Medicine, Zhejiang University, 79\#

Qingchun Road, Hangzhou 310003, Zhejiang, China

${ }^{2}$ Collaborative innovation center for Diagnosis treatment of infectious

diseases, 79\# Qingchun Road, Hangzhou 310003, Zhejiang, China

Full list of author information is available at the end of the article
}

relevant radiological and pathological characteristics. On the basis of literature review, imaging techniques that may contribute to the diagnosis and appropriate treatment measures are also discussed.

\section{Case presentation}

A 54-year-old Chinese male was referred to our hospital for further evaluation of a liver mass, which was discovered incidentally during routine physical examination in a local hospital. The patient had a 10-year history of hypertension and was diagnosed with diabetes mellitus approximately 5 years before. He denied history of liver cirrhosis and hepatitis B virus (HBV) or hepatitis $C$ virus $(\mathrm{HCV})$ infection. The patient underwent splenectomy 5 years earlier owing to a high-altitude falling accident. No mass was identifiable on abdominal palpation exam. Serum tumor markers (alpha-fetoprotein, CA199, and CA125) were within the normal range. Abdominal ultrasonography (US) revealed a $5 \mathrm{~cm}$ iso-echoic lesion that located in the left hepatic lobe near the capsule. A

(c) The Author(s). 2018 Open Access This article is distributed under the terms of the Creative Commons Attribution 4.0 International License (http://creativecommons.org/licenses/by/4.0/), which permits unrestricted use, distribution, and 
$1.2 \mathrm{~cm}$ gallstone was also observed. An abdominal plane-computed tomography (CT) scan revealed an oval, slightly hypodense mass located in segment IV of the left liver lobe measuring $4.5 \times 3.3 \mathrm{~cm}$. The lesion had an inhomogeneous enhancement during the arterial phase and diminished enhancement during the portal and equilibrium phases on a contrast-enhanced $\mathrm{CT}$ scan (Fig. 1). Abdominal magnetic resonance imaging (MRI) showed a slightly hypointense mass on both T1- and T2-weighted images, which appeared slightly hyperintense on diffusion-weighted images. After the injection of gadoxetic acid, the lesion appeared strongly heterogeneous and hyperintense during the arterial phase and relatively hypointense during the portal and equilibrium phases (Fig. 2). An indication of a pseudo-capsule was also observed. Partial hepatectomy and cholecystectomy were performed with the suspicion of hepatocellular carcinoma (HCC).

During the operation, the intrahepatic mass was found to be located in segment IV of the liver, measuring $4.0 \mathrm{~cm}$ in diameter. It was completely embedded in the liver tissue, and no other mass was found. Postoperative hematoxylin and eosin staining revealed sinusoidal structures and lymphoid tissue hyperplasia. A capsule separating the spleen tissue from liver tissue could be clearly detected (Fig. 3), which confirmed intrahepatic splenosis. Detailed immunohistochemical staining showed positivity for CD3 and CD20, specific markers for lymphocyte T cells and B cells, respectively. Meanwhile, the expression of the Ki-67 antigen was quite limited. The polyclonal nature of the lymphocytes and the low proliferation activity further confirmed the benign characteristic of the mass, as malignant tumors are always monoclonal with active proliferation. The patient discharged uneventfully after the operation, and no symptoms of recurrence have been observed during 2 years of follow-up.

\section{Literature review}

We searched the PubMed and Scopus databases for relevant English literature from the year 2000 through March 2018 using the Medical Subject Headings (MeSH) "Hepatocellular Carcinoma," "Liver Neoplasm," and "Splenosis." In total, 37 cases of intrahepatic splenosis were identified and reviewed [3-37]. Characteristics of the cases such as age and sex of patients, clinical symptoms, diagnostic modality, and location of the masses were reviewed and analyzed (Table 1). There were $31(83.8 \%)$ male and $6(16.2 \%)$ female patients, and the mean age of the patients was 49.2 years (ranging from 21 to 73 years).

In the 37 documented cases, 35 (94.6\%) patients had histories of trauma or/and splenectomy, and the mean time elapsing between trauma/splenectomy and diagnosis of intrahepatic splenosis was 24.9 years (ranging from 5 to 46 years). A total of $20(54.1 \%)$ patients had related liver diseases, among which 8 (40\%) had HBV infection, 11 (55\%) had HCV infection, and 11 (55\%) had cirrhosis. Most of the patients were asymptomatic upon admission, except for $6(16.2 \%)$ who had abdominal pain. US, CT, and MRI were common imaging techniques, but they did not clearly differentiate intrahepatic splenosis from other liver lesions, such as HCC, liver metastases, or liver adenoma. Scintigraphy was used in 7 (18.9\%) patients, and in 3 (42.9\%) of them, the imaging led to the correct diagnosis without further invasive measures. The majority of intrahepatic splenosis were located in the subcapsular region of the liver, surrounded by capsules. A total of 34 (91.9\%) patients had undergone invasive procedures. Surgery in 21 (61.8\%) patients, including laparoscopic resection and laparotomy, was the most common invasive procedure followed by biopsy in 13 (38.2\%).

\section{Discussion}

Splenosis represents the heterotopic autotransplantation and implantation of splenic tissue after elective splenectomy or traumatic spleen rupture. Once considered to be a rare condition, a recent estimated incidence is up to $67 \%$ of patients who have a history of splenic rupture or surgery [38]. Intrahepatic splenosis is still rare, as most of the splenoses were located in the mesentery, omentum, or peritoneum. Except for some extraordinary cases, almost all of the cases with intrahepatic splenosis have a history of splenic trauma or splenectomy $[11,19]$. Hence, intrahepatic splenosis should be taken into

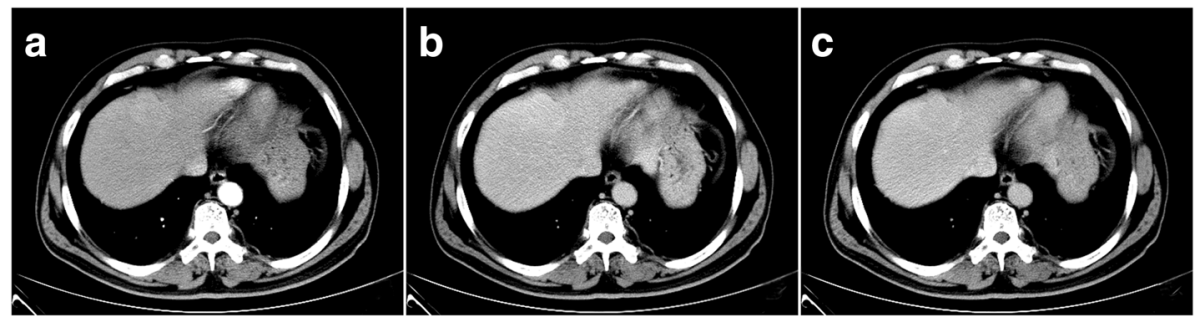

Fig. 1 Contrast-enhanced computed tomography scan of intrahepatic splenosis. The lesion had an inhomogeneous enhancement during the arterial phase (a) and diminished enhancement during the portal phase (b) and equilibrium phase(c) 

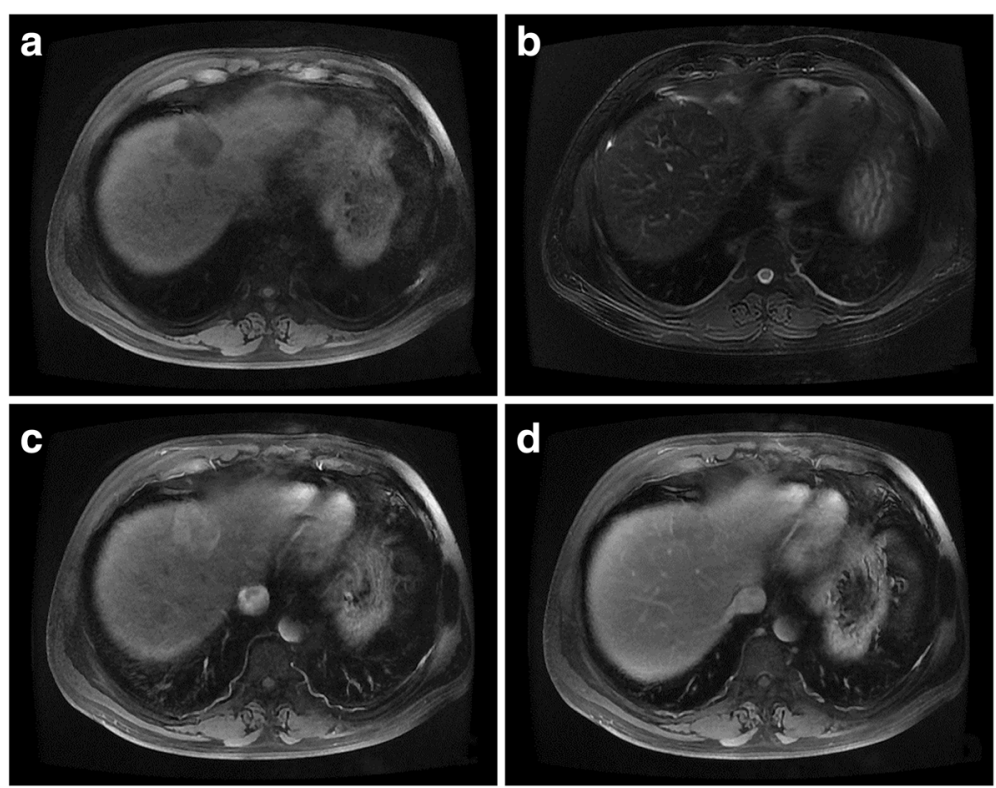

Fig. 2 Magnetic resonance imaging scan of intrahepatic splenosis. Note a slightly hypointense mass on both T1-weighted (a) and T2-weighted (b) images. After the injection of gadoxetic acid, the mass became strongly heterogeneous and hyperintense during the arterial phase (c) and relatively hypointense during the portal phase (d)

consideration in patients with a relevant history, especially if the mass is found to be located close to the liver capsule.

The absence of typical radiological features makes it difficult to reach a correct diagnose with common imaging techniques, such as US, CT, and MRI. As a result, intrahepatic splenosis can be confused with HCC, adenoma, or other liver diseases, leading to unnecessary surgery or other invasive treatments. Therefore, more sensitive novel methods to diagnose intrahepatic splenosis are needed. Scintigraphy with sensitive technetium-99 m-labeled heat-denatured red blood cells (Tc-99 m-DRBC) is reported to be the most specific and efficient diagnostic method [20]. As approximately $90 \%$ of damaged erythrocytes will be trapped by splenic tissue, remarkable differences in uptake of the radioactive isotope can be observed between intrahepatic splenic tissue and normal liver tissue. Krawczyk et al. [14], Grande et al. [27], and Pekkafali et al. [35] reported three cases that successfully avoided invasive treatments by using Tc- $99 \mathrm{~m}$-DRBC scintigraphy. Scintigraphy with sulfur colloid is considered to be another useful diagnostic method, but has a lower sensitivity in identification of splenosis [39]. Superparamagnetic

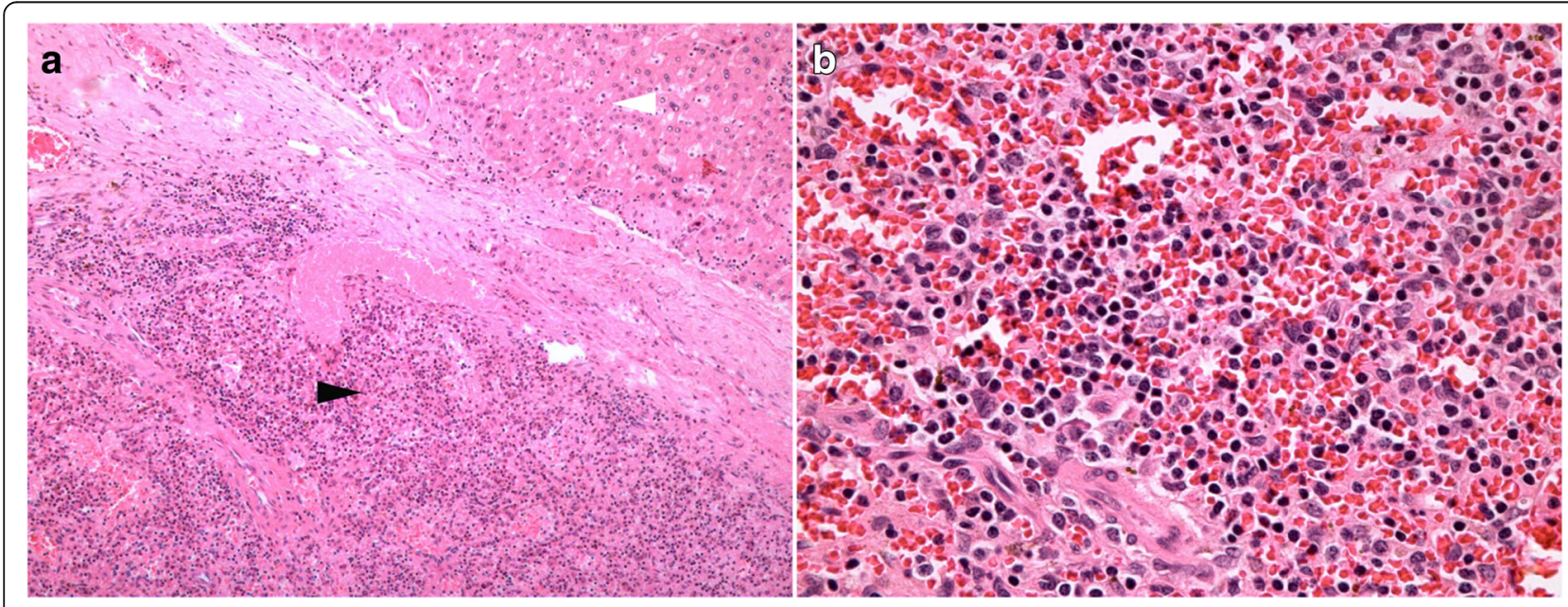

Fig. 3 Histopathological features of intrahepatic splenosis. Hematoxylin and eosin staining. a A capsule clearly separated the liver (white arrow) and spleen (black arrow) parenchyma, $\times 100$. b Intrahepatic splenosis with lymphoid tissue hyperplasia and sinusoidal structures, $\times 400$ 


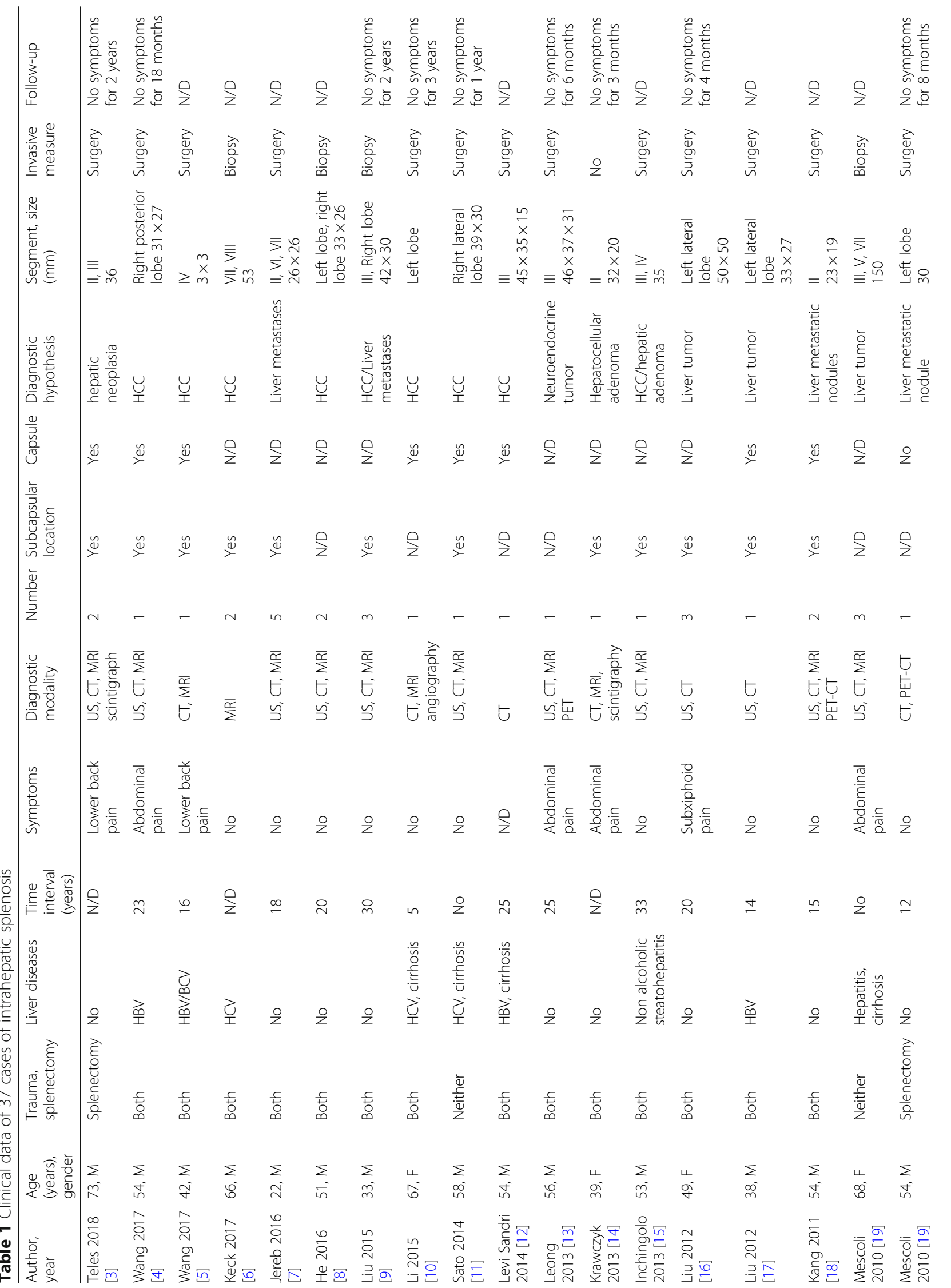




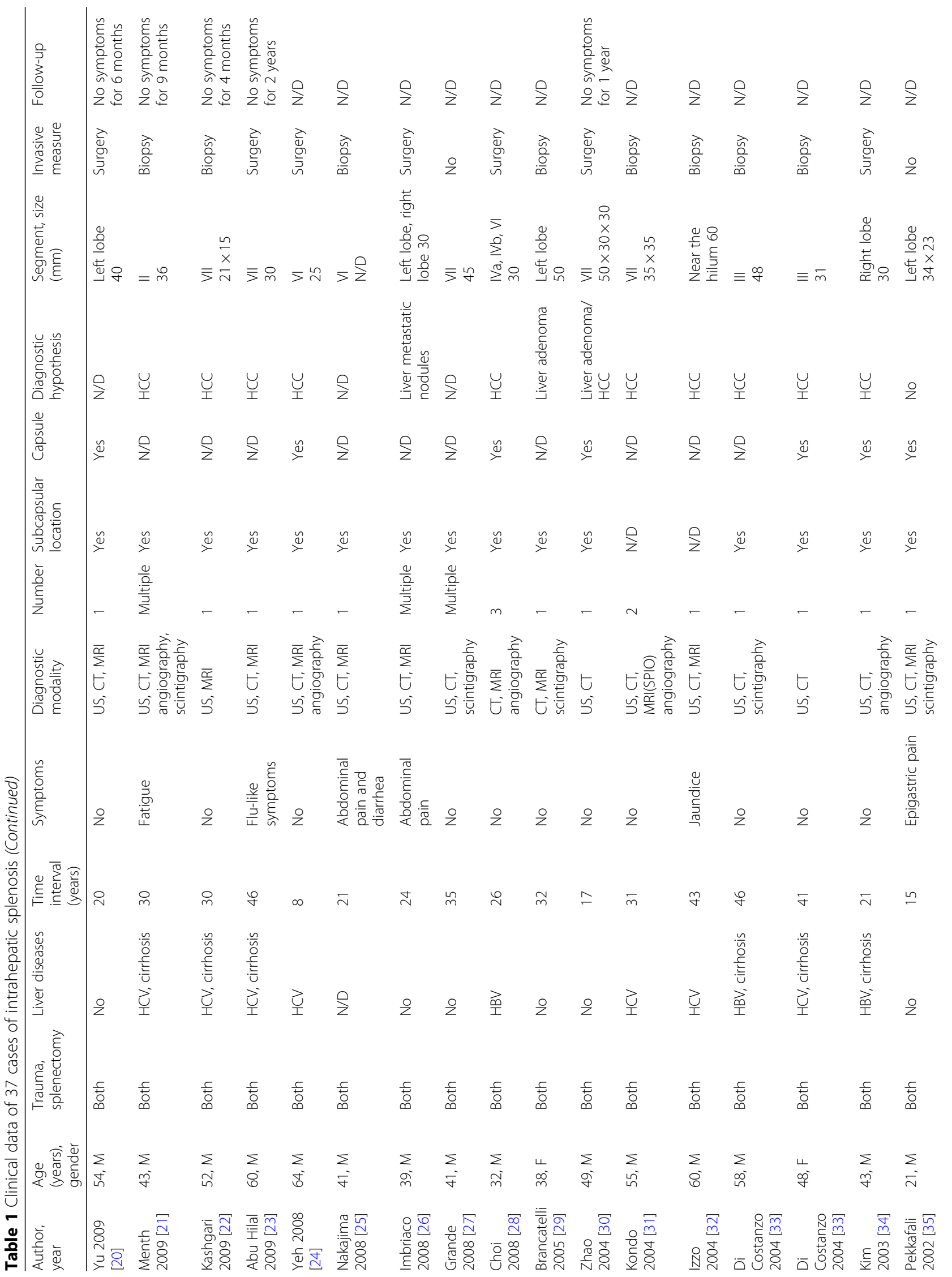




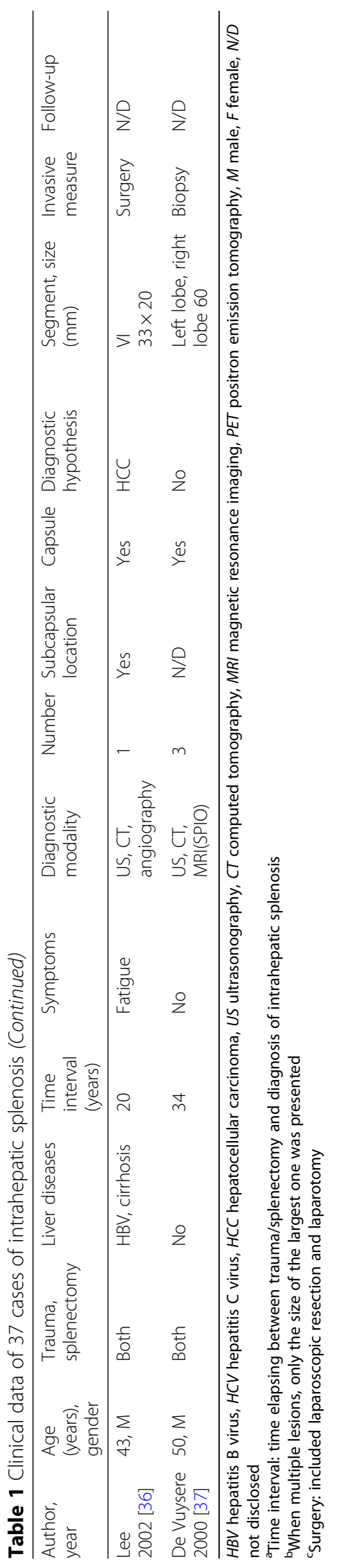


Table 2 Suspicious degree of intrahepatic mass to be splenosis

\begin{tabular}{|c|c|c|c|}
\hline \multirow[t]{2}{*}{ Parameters } & \multicolumn{2}{|l|}{ Score } & \multirow[t]{2}{*}{ Methods } \\
\hline & 0 & 1 & \\
\hline Alpha-fetoprotein & $\begin{array}{l}>400 \mu \mathrm{g} / \mathrm{L} \text { for } 4 \text { weeks } \\
>200 \mu \mathrm{g} / \mathrm{L} \text { for } 8 \text { weeks }\end{array}$ & No & ELISA \\
\hline Cirrhosis & Yes & No & US, CT, MRI \\
\hline Hepatitis & Yes & No & ELISA, PCR \\
\hline Splenic trauma & No & Yes & $\begin{array}{l}\text { History taking/ } \\
\text { US, CT, MRI }\end{array}$ \\
\hline Splenectomy & No & Yes & $\begin{array}{l}\text { History taking/ } \\
\text { US, CT, MRI }\end{array}$ \\
\hline Mass location & Non-subcapsular & subcapsular & US, CT, MRI \\
\hline Mass capsule & No & Yes & US, CT, MRI \\
\hline Howell-Jolly and Heinz bodies after splenectomy & Yes & No & Hematological examination \\
\hline
\end{tabular}

ELISA enzyme-linked immunosorbent assay, US ultrasonography, CT computed tomography, MRI magnetic resonance imaging, $P C R$ polymerase chain reaction ${ }^{\mathrm{a}}$ For alpha-fetoprotein, exclude pregnancy, acute severe hepatitis, embryonic gonad tumors, and other digestive system tumor

iron oxide (SPIO) contrast magnetic resonance imaging may be helpful for the diagnosis of splenosis. As reported, intrahepatic splenosis will remain hyperintense relative to the liver parenchyma, while $\mathrm{HCC}$ will become hypointense after the SPIO administration [37].

In fact, most of the cases with intrahepatic splenosis that had been reported were treated with invasive procedures, including biopsy and surgical resection. However, intrahepatic splenosis may be beneficial in the patients who have undergone splenectomy, since it can replace part of the immunologic function of the removed spleen [40]. Hence, conservative treatment is strongly recommended for asymptomatic intrahepatic splenosis, except for some special situations, such as idiopathic thrombocytopenic purpura and Felty syndrome.

In order to avoid unnecessary invasive treatment, accurate diagnosis is essential. Although some novel imaging methods, such as scintigraphy, have shown promising application prospects in diagnosis of intrahepatic splenosis, they will not likely be used worldwide for quite some time. Instead, we think it may be helpful to use a scoring system to evaluate the suspicious degree of intrahepatic mass to be splenosis (Table 2). Compared with the CT/MRI Li-Rads v2017 [41], our scoring system seems to be more effective in diagnosing intrahepatic splenosis. The major imaging features (washout, enhancing "capsule" and threshold growth) of Li-Rads were not enough to distinguish intrahepatic splenosis from liver neoplasm. According to the table, the higher the total score is, the stronger is the possibility that the mass will be splenosis. When the total score is greater than 3, it is better to use biopsy to clarify the diagnosis, instead of taking more aggressive measures directly.

\section{Conclusion}

Although isolated intrahepatic splenosis is rarely encountered, it should be taken into account in the differential diagnosis of a liver lesion, especially if the patient has a history of splenic trauma or splenectomy. The proposed scoring system may be useful in diagnosing intrahepatic splenosis when effective diagnostic methods, like scintigraphy and SPIO MRI, are lacking. If intrahepatic splenosis has been confirmed, conservative treatment is strongly recommended for the patient without any symptoms.

\section{Abbreviations}

CT: Computed tomography; ELISA: Enzyme-linked immunosorbent assay; PCR: Polymerase chain reaction; F: Female; HBV: Hepatitis B virus;

HCC: Hepatocellular carcinoma; HCV: Hepatitis C virus; M: Male; MeSH: Medical Subject Headings; MRI: Magnetic resonance imaging; N/D: Not disclosed; PET: Positron emission tomography;

SPIO: Superparamagnetic iron oxide; Tc-99 m-DRBC: Technetium-99 m-labeled heat-denatured red blood cells; US: Ultrasonography

\section{Funding}

This work was supported by the Major program of National Natural Science Foundation of China (91542205) to SSZ, the National Natural Science

Foundation of China (81570575) to PHS.

\section{Authors' contributions}

SSZ performed the partial hepatectomy and cholecystectomy, and designed the analysis. ZFX and JC drafted the manuscript. DLW reviewed the literature; PHS and YHD supervised the draft and managed the patient's follow-up. LWW participated in the interpretation of pathological data. All authors read and approved the final manuscript.

Ethics approval and consent to participate

The ethics committee of First Affiliated Hospital, School of Medicine, Zhejiang University approved the study.

\section{Consent for publication}

Written informed consent was obtained from the patient for publication of this case report and any accompanying images.

Competing interests

The authors declare that they have no competing interests.

\section{Publisher's Note}

Springer Nature remains neutral with regard to jurisdictional claims in published maps and institutional affiliations. 


\section{Author details}

Division of Hepatobiliary and Pancreatic Surgery, Department of Surgery, First Affiliated Hospital, School of Medicine, Zhejiang University, 79\# Qingchun Road, Hangzhou 310003, Zhejiang, China. ${ }^{2}$ Collaborative innovation center for Diagnosis treatment of infectious diseases, 79\# Qingchun Road, Hangzhou 310003, Zhejiang, China. ${ }^{3}$ Department of Pathology, First Affiliated Hospital, School of Medicine, Zhejiang University, 79\# Qingchun Road, Hangzhou 310003, Zhejiang, China.

Received: 2 May 2018 Accepted: 22 June 2018

Published online: 28 June 2018

\section{References}

1. Fleming CR, Dickson ER, Harrison EG Jr. Splenosis: autotransplantation of splenic tissue. Am J Med. 1976;61:414-9.

2. Fremont RD, Rice TW. Splenosis: a review. South Med J. 2007;100:589-93.

3. Teles GNS, Monteiro PEZ, Raphe R. Intrahepatic splenosis mimicking hepatic neoplasia. Int J Surg Case Rep. 2018;44:47-50.

4. Wang WC, Li XF, Yan ZL, Wang Y, Ma JY, Shi LH, et al. Intrahepatic splenosis mimics hepatocellular carcinoma in a patient with chronic hepatitis $B$ : a case report and literature review. Medicine (Baltimore). 2017;96:e8680.

5. Wang MY, Li B, Chen D, Liu AL, Qamar S, Sun MY. Spleen implanting in the fatty liver mimicking hepatocarcinoma in a patient with hepatitis B\&C: a case report and literature review. Medicine (Baltimore). 2017:96:e7217.

6. Keck C, Shetty A, Mischen B, Willner I. Hepatic Splenosis masquerading as hepatocellular carcinoma in a chronic hepatitis C patient. Am J Gastroenterol. 2017;112:1493.

7. Jereb S, Trotovsek B, Skrbinc B. Hepatic splenosis mimicking liver metastases in a patient with history of childhood immature teratoma. Radiol Oncol. 2016:50:212-7

8. He Z, Xu X, Ke Q, Zheng S. Successful diagnosis of intrahepatic splenosis mimicking hepatic tumor. Kaohsiung J Med Sci. 2016;32:224-5.

9. Liu C, Liu J, Wang F. Intrahepatic splenosis mimicking liver cancer: report of a case and review of literature. Int J Clin Exp Pathol. 2015;8:1031-5.

10. Li T, Yang XY, Tang ZY. Intrahepatic and intraperitoneal splenosis mimicking hepatocellular carcinoma with abdominal wall metastasis in a patient with hepatitis C cirrhotic liver. Surgery. 2015;157:954-6.

11. Sato N, Abe T, Suzuki N, Waragai M, Teranishi Y, Takano Y, et al. Intrahepatic splenosis in a chronic hepatitis C patient with no history of splenic trauma mimicking hepatocellular carcinoma. Am J Case Rep. 2014;15:416-20.

12. Levi Sandri GB, Lai Q, Bosco S, Berloco PB. Liver splenosis mimicking hepatocellular carcinoma in cirrhotic liver. Liver Int. 2014;34:162.

13. Leong CW, Menon T, Rao S. Post-traumatic intrahepatic splenosis mimicking a neuroendocrine tumour. BMJ Case Rep. 2013;2013.

14. Krawczyk M, Schneider G, Farmakis G, Zimmer V, Lammert F. Splenosis mimicking hepatic adenoma. J Clin Exp Hepatol. 2013;3:351-2.

15. Inchingolo R, Peddu P, Karani J. Hepatic splenosis presenting as arterialised liver lesion in a patient with NASH. Eur Rev Med Pharmacol Sci. 2013;17:2853-6.

16. Liu Y, Ji B, Wang G, Wang Y. Abdominal multiple splenosis mimicking liver and colon tumors: a case report and review of the literature. Int J Med Sci. 2012:9:174-7.

17. Liu K, Liang Y, Liang X, Yu H, Wang Y, Cai X. Laparoscopic resection of isolated hepatic splenosis mimicking liver tumors: case report with a literature review. Surg Laparosc Endosc Percutan Tech. 2012;22:e307-11.

18. Kang KC, Cho GS, Chung GA, Kang GH, Kim YJ, Lee MS, et al. Intrahepatic splenosis mimicking liver metastasis in a patient with gastric cancer. J Gastric Cancer. 2011;11:64-8.

19. Mescoli C, Castoro C, Sergio A, Ruol A, Farinati F, Rugge M. Hepatic spleen nodules (HSN). Scand J Gastroenterol. 2010;45:628-32.

20. Yu H, Xia L, Li T, Ju M, Liu L, Wu Z, et al. Intrahepatic splenosis mimicking hepatoma. BMJ Case Rep. 2009;2009.

21. Menth M, Herrmann K, Haug A, Raziorrouh B, Zachoval R, Jung CM, et al. Intra-hepatic splenosis as an unexpected cause of a focal liver lesion in a patient with hepatitis C and liver cirrhosis: a case report. Cases J. 2009;2: 8335

22. Kashgari AA, Al-Mana HM, Al-Kadhi YA. Intrahepatic splenosis mimicking hepatocellular carcinoma in a cirrhotic liver. Saudi Med J. 2009;30:429-32.

23. Abu Hilal M, Harb A, Zeidan B, Steadman B, Primrose JN, Pearce NW. Hepatic splenosis mimicking HCC in a patient with hepatitis $C$ liver cirrhosis and mildly raised alpha feto protein; the important role of explorative laparoscopy. World J Surg Oncol. 2009;7:1.

24. Yeh ML, Wang LY, Huang Cl, Hsieh MY, Lin ZY, Chuang WL, et al. Abdominal splenosis mimicking hepatic tumor: a case report. Kaohsiung J Med Sci. 2008;24:602-6.

25. Nakajima T, Fujiwara A, Yamaguchi M, Makiyama A, Wakae T, Fujita K, et al. Intrahepatic splenosis with severe iron deposition presenting with atypical magnetic resonance images. Intern Med. 2008;47:743-6.

26. Imbriaco M, Camera L, Manciuria A. Salvatore M.A case of multiple intraabdominal splenosis with computed tomography and magnetic resonance imaging correlative findings. World J Gastroenterol. 2008;14:1453-5.

27. Grande M, Lapecorella M, lanora AA, Longo S, Rubini G. Intrahepatic and widely distributed intraabdominal splenosis: multidetector CT. US and scintigraphic findings. Intern Emerg Med. 2008;3:265-7.

28. Choi GH, Ju MK, Kim JY, Kang CM, Kim KS, Choi JS, et al. Hepatic splenosis preoperatively diagnosed as hepatocellular carcinoma in a patient with chronic hepatitis B: a case report. J Korean Med Sci. 2008:23:336-41.

29. Brancatelli G, Vilgrain V, Zappa M, Lagalla R. Case 80: splenosis. Radiology. 2005;234:728-32.

30. Zhao M. Xu HW.Splenosis simulating an intrahepatic mass. Chin J Traumatol. 2004;7:62-4.

31. Kondo M, Okazaki H, Takai K, Nishikawa J, Ohta H, Uekusa T, et al. Intrahepatic splenosis in a patient with chronic hepatitis C. J Gastroenterol. 2004:39:1013-5.

32. Izzo L, Caputo M, Galati G. Intrahepatic accessory spleen: imaging features. Liver Int. 2004:24:216-7.

33. Di Costanzo GG, Picciotto FP, Marsilia GM, Ascione A. Hepatic splenosis misinterpreted as hepatocellular carcinoma in cirrhotic patients referred for liver transplantation: report of two cases. Liver Transpl. 2004;10:706-9.

34. Kim KA, Park CM, Kim CH, Choi SY, Park SW, Kang EY, et al. An interesting hepatic mass: splenosis mimicking a hepatocellular carcinoma (2003,9b). Eur Radiol. 2003;13:2713-5

35. Pekkafali Z, Karsli AF, Silit E, Basekim CC, Narin Y, Mutlu H, et al. Intrahepatic splenosis: a case report. Eur Radiol. 2002;12(Suppl 3):S62-5.

36. Lee JB, Ryu KW, Song TJ, Suh SO, Kim YC, Koo BH, et al. Hepatic splenosis diagnosed as hepatocellular carcinoma: report of a case. Surg Today. 2002; 32:180-2

37. De Vuysere S, Van Steenbergen W, Aerts R, Van Hauwaert H, Van Beckevoort D, Van Hoe L. Intrahepatic splenosis: imaging features. Abdom Imaging. 2000;25:187-9

38. Case records of the Massachussetts General Hospital. Weekly clinicopathological exercises. Case 29-1995.65-year-old man with mediastinal Hodgkin's disease and a pelvic mass. N Engl J Med. 1995; 333:784-91

39. Hagan I, Hopkins R, Lyburn I. Superior demonstration of splenosis by heatdenatured Tc-99m red blood cell scintigraphy compared with Tc-99m sulfur colloid scintigraphy. Clin Nucl Med. 2006;31:463-6.

40. Hathaway JM, Harley RA, Self S, Schiffman G, Virella G. Immunological function in post-traumatic splenosis. Clin Immunol Immunopathol. 1995; 74:143-50.

41. Elsayes KM, Hooker JC, Agrons MM, Kielar AZ, Tang A, Fowler KJ, et al. Version of LI-RADS for CT and MR imaging: an update. Radiographics. 2017; 37:1994-2017.

Ready to submit your research? Choose BMC and benefit from

- fast, convenient online submission

- thorough peer review by experienced researchers in your field

- rapid publication on acceptance

- support for research data, including large and complex data types

- gold Open Access which fosters wider collaboration and increased citations

- maximum visibility for your research: over $100 \mathrm{M}$ website views per year

At BMC, research is always in progress.

Learn more biomedcentral.com/submissions 